\title{
RESEARCH
}

Open Access

\section{Predictors of lower extremity amputation in patients with diabetic foot ulcer: findings from MEDFUN, a multi-center observational study}

Ejiofor Ugwu ${ }^{1 *}$ (D), Olufunmilayo Adeleye ${ }^{2}$, Ibrahim Gezawa ${ }^{3}$, Innocent Okpe ${ }^{4}$, Marcelina Enamino ${ }^{5}$ and Ignatius Ezeani ${ }^{6}$

\begin{abstract}
Background: Lower extremity amputation (LEA) is a potential sequelae of diabetic foot ulceration (DFU) and is associated with huge morbidly and mortality. Low and middle income countries are currently at the greatest risk of diabetes-related complications and deaths. We sought to identify demographic, clinical and laboratory variables that significantly predict LEA in patients hospitalized for DFU.

Methods: The Multi-center Evaluation of Diabetic Foot Ulcer in Nigeria (MEDFUN) was an observational study conducted between March 2016 and April 2017 in six tertiary healthcare institutions. We prospectively followed 336 diabetic patients hospitalized for DFU and managed by a multidisciplinary team until discharge or death. Demographic and diabetesrelated information and ulcer characteristics were documented. Patients were evaluated for neuropathy, peripheral arterial disease (PAD) and medical co-morbidities while relevant laboratory and imaging tests were performed. The study endpoints were ulcer healing, LEA, duration of hospitalization and mortality. Here we present data on amputation.

Results: One hundred and nineteen subjects (35.4\%) underwent LEA during the follow-up period. Univariate predictors of LEA were ulcer duration more than 1 month prior to hospitalization $(P<0.001)$, PAD $(P<0.001)$, Wagner grade $\geq 4(P$ $<0.001$ ), wound infection (P 0.041), Proteinuria (P 0.021), leucocytosis ( $P$ 0.001) and osteomyelitis $(P<0.001)$. On multivariate regression, only three variables emerged as significant independent predictors of LEA and these include: ulcer duration more than 1 month (O.R. 10.3, 95\% C.I. 4.055-26.132), PAD (O.R. 2.8, 95\% C.I. 1.520-5.110) and presence of osteomyelitis (O.R. 5.6, 95\% C.I. 2.930-10.776). Age, gender, diabetes type and duration, neuropathy, glycemic control and anemia did not predict LEA in the studied population.

Conclusion: We identified duration of ulcer greater than 1 month, PAD, Wagner grade 4 or higher, proteinuria, leucocytosis, wound infection and osteomyelitis as the significant predictors of LEA in patients hospitalized for DFU. Prompt attention to these risk factors may reduce amputation rate among these patients.
\end{abstract}

Keywords: Diabetes, Foot ulcer, Risk factors, Amputation, Predictors, MEDFUN, Nigeria, Africa

\footnotetext{
* Correspondence: ofornet@yahoo.com

'Department of Medicine, Division of Endocrinology, Diabetes and

Metabolism, Enugu State University of Science and Technology, Enugu,

Nigeria

Full list of author information is available at the end of the article
}

(C) The Author(s). 2019 Open Access This article is distributed under the terms of the Creative Commons Attribution 4.0 International License (http://creativecommons.org/licenses/by/4.0/), which permits unrestricted use, distribution, and reproduction in any medium, provided you give appropriate credit to the original author(s) and the source, provide a link to the Creative Commons license, and indicate if changes were made. The Creative Commons Public Domain Dedication waiver (http://creativecommons.org/publicdomain/zero/1.0/) applies to the data made available in this article, unless otherwise stated. 


\section{Background}

As a result of the relentless increase in the prevalence of diabetes mellitus (DM) in Africa, a corresponding rise in diabetes complications is expected. The International Diabetes Federation and World Health Organization jointly warn that these complications, if unchecked would threaten the viability of many African nations [1]. With diabetes prevalence of $5.7 \%$, Nigeria is currently home to about 5 million adults living with diabetes. This appears to be a tip of the iceberg as it is estimated that about two-thirds of diabetes cases in Nigeria are yet undiagnosed [2]. Consequent upon this high prevalence of chronic undetected hyperglycemia, many individuals with diabetes present with already established chronic complications at the time of diagnosis [3].

One potentially preventable complication of diabetes that is associated with high morbidity and mortality is diabetic foot ulcer (DFU). It is estimated that a person with diabetes has up to $25 \%$ chance of developing DFU in his/her lifetime [4]. The burden of DFU is high both in Africa generally [5], and in Nigeria in particular [6, 7]. A recent update suggests that nearly 2 out of every 10 out-patients with diabetes in Nigeria have diabetic foot disease [7], and DFU accounts for nearly a third of diabetes-related hospital admissions [8]. Diabetic foot ulcer is associated with prolonged hospital stay, substantial economic burden and high mortality $[9,10]$. Perhaps the most unpleasant potential consequence of DFU besides death is lower extremity amputation (LEA).

More than three-quarters of all LEAs performed in people with diabetes is secondary to DFU which is currently the leading cause of non-trauma related LEA globally [11]. The negative medical and psychosocial consequences of LEA in people with DM are substantial. About $10 \%$ of those who suffer major LEAs die intraadmission [12]. And post LEA survivors have a significantly reduced quality of life and higher risk of depression which may be related to impaired psychosocial functioning [13]. The long term prognosis after DFU-related LEA is also reportedly abysmal, with 3-year mortality after diabetic foot amputation ranging from 35 to 50\% [14]. In fact, long term prognosis after major LEAs in people with diabetes has been shown to be comparable to breast and prostate malignancies in females and males respectively [15].

Diabetes-related LEA rates have significantly declined in many Western countries $[16,17]$. This is however not the case in many parts of Africa where DFU-related LEA rates are still very high [5]. Less than half a decade ago, amputation rate as high as $52 \%$ was reported among patients hospitalized for DFU in one tertiary healthcare center in Nigeria [6]. Efforts to prevent this unpleasant scenario therefore deserve utmost attention, and this could be partly accomplished by risk factor identification. Regrettably, not much has been done in this direction in Nigeria.
This research represents an effort to fill this very important gap.

\section{Methods}

The Multi-center Evaluation of Diabetic Foot Ulcer in Nigeria (MEDFUN) was a 1 year prospective observational study conducted in six tertiary healthcare institutions across Nigeria, from March 2016 to April 2017. The centers included Enugu State University Teaching Hospital, Lagos State University Teaching Hospital, Aminu Kano Teaching Hospital, Ahmadu Bello University Teaching Hospital Zaria, Federal Medical Center Keffi and Federal Medical Center Umuahia. The inclusion criterion was all consenting adults $\geq 18$ years with type 1 or type 2 diabetes hospitalized for DFU over the study period. Approval of the study protocol was obtained from the local Research and Ethics committee of each of the hospitals while verbal informed consent was obtained from each patient prior to recruitment.

Details of the methodology of the MEDFUN study have been published [18]. Summarily, we obtained relevant socio-demographic and diabetes-related information including gender, age, occupation, cigarette smoking status, diabetes type and duration. Distinction between type 1 and type $2 \mathrm{DM}$ was made clinically based on combined parameters of age and method of diabetes control. Subjects who had been exclusively controlled on insulin since the time of diagnosis were classified as type 1 diabetes (T1DM) while those who were being treated with oral anti-diabetic drugs (OAD) with or without insulin were adjudged to have type 2 diabetes mellitus (T2DM).

Participants' knowledge of proper foot care practices was assessed. This entailed inquiries about bare-foot walking, daily foot inspection, proper foot wear, use of emollients to prevent dryness of the feet, proper pedicure practice and early treatment of foot problems. They were also asked whether they had received any foot care education prior to foot ulceration. History of development and progression of ulcer including mechanism of ulceration, site of ulcer, duration of ulcer and prior ulcer treatment methods were also assessed. The severity of ulcer was graded using the Wagner grading system. This widely used DFU grading system, although has some limitations including not taking into account, wound size and vascular integrity of the foot, has the advantages of simplicity and ease of bedside application compared to newer wound classification systems. It does not require sophisticated laboratory or imaging tests and is therefore especially suitable for developing countries like ours with constrained resources. Besides, the Wagner grading system has been shown to have strong correlations with DFU outcomes in several studies. Clinical wound infection was determined according to the International Working Group on Diabetic Foot guideline (4) by the presence of purulent exudates or any two or more of the following: 
periwound edema, periwound redness, local warmth, foul smell, pain or tenderness on palpation and fever. Commonly known risk factors for DFU were also evaluated, including history of previous DFU, barefoot walking, improper foot wear, visual impairment, foot deformity, peripheral neuropathy and peripheral artery disease (PAD). Peripheral neuropathy was diagnosed by loss of pressure perception to Semmes-Weinstein $10 \mathrm{~g}$ monofilament test or diminished vibration sense using the $128 \mathrm{~Hz}$ tunning fork. Peripheral artery disease was suspected in the presence of diminished or impalpable dorsalis pedis and/or posterior tibial artery pulsations on manual examination, and then confirmed by the presence of significant arterial narrowing $(>50 \%)$ on Doppler ultrasonography of the lower limbs.

Relevant laboratory and imaging studies were performed for each subject including urine protein, complete blood count, glycated hemoglobin (HbA1c), blood culture, ulcer specimen culture, lipid profile, plain radiograph of the foot and Doppler ultrasonography of both lower limbs. Co-morbid complications including hypertension, anemia, shock, hyperglycemic emergency, hypoglycemia, stroke, kidney disease and cardiac failure were explored and documented.

Every patient received appropriate multi-disciplinary care including bed rest, wound debridement, daily wound dressing, antibiotic therapy, skin grafting and limited amputation in addition to control of blood glucose and treatment of associated co-morbidities. Follow up was continued until the patient was discharged from the hospital or exited by death. Outcome variables of interest included ulcer healing, amputation, duration of hospitalization and mortality. We defined amputation above the mid-tarsal bone or involving the big toe as major amputation, otherwise it was considered as minor amputation. There are no generally accepted criteria for classifying amputation as major or minor. Our definition was therefore arbitrary and based on the potential physical limitations imposed by amputation of or above the big toe as the latter is responsible for $40 \%$ of weight bearing on the toes, and also the last part of the foot to push off the ground during walking. At the end of subject recruitment, records of medical admissions over the study period were retrospectively reviewed in all the centers to determine the total number of medical admissions and diabetes-related admissions. Descriptive data of the entire study population have been published [18]. We hereby present results of sub-analysis of data related to amputation.

\section{Statistical analysis}

For the current sub-analysis, we performed unadjusted associations between demographic, clinical and laboratory variables and amputation (whether major or minor) using the Chi-Square statistics for categorical variables and t-test for continuous variables. To identify independent predictors of amputation, we first performed univariate logistic regressions for each variable with amputation as the dependent outcome, and calculated variable odds ratios (ORs) and 95\% confidence intervals (CI). All the variables that emerged as significant predictors at this univariate level of analysis were then simultaneously entered into a multivariate regression model that was reduced using a backward selection method. Model reliability was determined by the Hosmer and Lemeshow test of goodness of fit. Analysis was done with the Statistical Package for Social Sciences (IBM version 23.0; SPSS Inc., Chicago, IL, USA). All tests were 2tailed and $P<0.05$ was considered significant.

\section{Results}

One hundred and nineteen (35.4\%) out of the 336 subjects that participated in this study underwent LEA and $75.6 \%$ of these were major amputations. Table 1 shows the comparisons between those who suffered LEA and those who did not. Subjects who underwent LEA had significantly longer pre-hospitalization duration of ulcer than those whose ulcers healed ( $63.9 \pm 57.8$ days vs. 35.0 \pm 22.1 days; $P<0.001)$. They also suffered more peripheral artery disease $(P<0.001)$, had higher Wagner grades of ulcers $(P<0.001)$, more prevalent wound infection ( $P$ 0.039) and higher baseline levels of acute phase reactants (WBC and ESR).

Table 2 shows univariate predictors of amputation among the study participants. Subjects with duration of ulcer more than 1 month were 10 times more likely to suffer LEA (95\% CI 4.656-21.567; $P<0.001$ ). Patients who had PAD $(P<0.001)$, Wagner grade 4 ulcer or higher $(P<0.001)$ and clinical wound infection $(P$ 0.041) were approximately 4 times, 6 times and twice as likely to undergo LEA respectively.

The outcome of a multivariate regression analysis of all the factors entered at the univariate level is presented in Table 3. Ulcer duration more than 1 month was the strongest independent predictor of LEA after adjusting for all other variables (adjusted OR 10.29; 95\% CI 4.055-26.132). This was followed by osteomyelitis (adjusted OR 5.62) and presence of PAD (adjusted OR 2.79).

\section{Discussion}

Besides death, lower extremity amputation is the most unpleasant consequence of diabetic foot ulcers, with far reaching medical and psycho-social impact. Outcome prediction in patients with DFU is likely to assist clinicians in prompt and appropriate decision making including individualization and optimization of available therapeutic options and resources. In spite of a growing burden of diabetes and diabetic foot ulcers in developing 
Table 1 Demographic, clinical and laboratory characteristics of subjects who underwent lower extremity amputation and those who did not

\begin{tabular}{|c|c|c|c|c|}
\hline \multirow[t]{2}{*}{ Variable } & \multirow[t]{2}{*}{ Total $(n=336)$} & \multicolumn{2}{|l|}{ Amputation } & \multirow[t]{2}{*}{$P$ value } \\
\hline & & Yes & No & \\
\hline Age (years) & $55.9 \pm 12.5$ & $56.8 \pm 11.3$ & $55.6 \pm 13.1$ & 0.391 \\
\hline Gender (male) & $185(55.1)$ & $67(36.2)$ & $118(63.8)$ & 0.734 \\
\hline Diabetes type (type 1) & $13(3.9)$ & $1(7.7)$ & $12(92.3)$ & 0.033 \\
\hline Diabetes duration (years) & $8.5 \pm 5.7$ & $9.1 \pm 5.7$ & $8.1 \pm 5.7$ & 0.130 \\
\hline Ulcer duration (days) & $45.2 \pm 41.0$ & $63.9 \pm 57.8$ & $35.0 \pm 22.1$ & $<0.001$ \\
\hline Ulcer duration (> 1 month) & $237(70.5)$ & $111(46.8)$ & $126(53.2)$ & $<0.001$ \\
\hline Neuropathy & $262(78.0)$ & $93(35.5)$ & $169(64.5)$ & 0.954 \\
\hline PAD & $176(52.4)$ & $87(49.4)$ & 89 (50.6) & $<0.001$ \\
\hline \multicolumn{5}{|l|}{ Wagner grades } \\
\hline Grade 1 & $13(3.9)$ & $0(0.0)$ & $13(100.0)$ & \\
\hline Grade 2 & $57(17.0)$ & $3(5.3)$ & $54(94.7)$ & \\
\hline Grade 3 & $88(26.2)$ & $22(25.0)$ & $66(75.0)$ & \multirow[t]{3}{*}{$<0.001$} \\
\hline Grade 4 & $124(36.9)$ & $58(46.8)$ & $66(53.2)$ & \\
\hline Grade 5 & $54(16.1)$ & $36(66.7)$ & $18(33.3)$ & \\
\hline Presence of gangrene & $178(53.0)$ & $94(52.8)$ & $84(47.2)$ & $<0.001$ \\
\hline Wound infection & $258(76.8)$ & 99 (38.4) & $159(61.6)$ & 0.039 \\
\hline Proteinuria & $96(28.6)$ & $54(44.6)$ & $67(55.4)$ & 0.021 \\
\hline HbA1c (\%) & $9.6 \pm 1.9$ & $9 . .9 \pm 1.8$ & $9.4 \pm 2.0$ & 0.061 \\
\hline White cell count (cells/ml) & $12.2 \pm 6.0$ & $13.5 \pm 5.9$ & $11.4 \pm 5.9$ & 0.003 \\
\hline ESR (mm/hour) & $63.3 \pm 34.8$ & $75.4 \pm 34.5$ & $56.2 \pm 33.0$ & $<0.001$ \\
\hline Osteomyelitis & $91(27.1)$ & $59(64.8)$ & $32(35.2)$ & $<0.001$ \\
\hline Anemia & $180(53.6 \%)$ & $71(39.4)$ & $109(60.6)$ & 0.097 \\
\hline Renal impairment & $66(19.6 \%)$ & $29(43.9)$ & $37(56.1)$ & 0.106 \\
\hline
\end{tabular}

Data are in numbers (percentage) or means ( \pm SD)

$P A D$ peripheral artery disease, $H b A 1 c$ glycated hemoglobin, ESR erythrocyte sedimentation rate

countries of Africa, published data on risk factors for LEA in this population are nonexistent.

In contrast to a Turkish study [19], we observed no significant association between age and LEA. Our observation is supported by many other studies which had demonstrated a lack of association between age and LEA in patients with DFU [20-22]. Although wound healing is generally slower in older than younger people, other factors beyond age such as nutritional status, vascular integrity and infection have been shown to play more dominant roles [23]. It is arguable that the younger age of our study population whose mean was $55.9 \pm 12.5$ years compared to that of the above cited study [19] with mean age of $62.65 \pm 10.6$ years might account for these divergent observations. However, in a large cohort of 2831 patients with DFU prospectively followed until healing or amputation, Gershater et al. [24] reported complete ulcer healing without amputation in $51 \%$ of patients older than 80 years and concluded that demographic variables including age, gender and duration of diabetes did not significantly predict amputation similar to our observations.

A longer duration of ulcer was strongly associated with LEA in this study. Our data revealed that ulcer longer than 1 month duration increased amputation risk ten folds even after adjustment for other confounding variables. Published studies that examined this variable on DFU outcome are scanty. Our observation is however in concordance with that of Uysal et al. [25] and may be explained by the fact that a longer duration of ulcer increases the probability of wound infection with resultant tissue necrosis. This notion is supported by Lavery et al. [26] who had demonstrated that ulcer duration more than 30 days was associated with a three-fold increase in wound infection. Both Wang et al. [20] and Tabur et al. [27] reported that wound infection increased amputation risk several folds. In confirmation of their findings, wound infection resulted in nearly twice the risk of amputation in our study, although this relationship became attenuated on multivariate analysis. However, bone infection/osteomyelitis 
Table 2 Univariate predictors of amputation

\begin{tabular}{|c|c|c|c|c|c|}
\hline \multirow[t]{2}{*}{ Variable } & \multicolumn{2}{|c|}{ Amputation } & \multirow[t]{2}{*}{$P$ value } & \multirow[t]{2}{*}{ OR } & \multirow[t]{2}{*}{$95 \%$ C.I } \\
\hline & $\begin{array}{l}\text { Yes } \\
\text { n (\%) }\end{array}$ & $\begin{array}{l}\text { No } \\
\text { n (\%) }\end{array}$ & & & \\
\hline Age $\geq 65$ years & $29(37.2)$ & $49(62.8)$ & 0.874 & 1.065 & $0.488-2.325$ \\
\hline Gender (male) & $67(36.2)$ & $118(63.8)$ & 0.734 & 1.081 & $0.689-1.695$ \\
\hline Diabetes type (type 1) & $1(7.7)$ & $12(92.3)$ & 0.065 & 0.145 & $0.019-1.127$ \\
\hline Diabetes duration $>10$ years & $35(40.7)$ & $51(59.3)$ & 0.236 & 1.356 & $0.819-2.245$ \\
\hline Ulcer duration > 1 month & $111(46.8)$ & $126(53.2)$ & $<0.001$ & 10.021 & $4.656-21.567$ \\
\hline Neuropathy & $93(35.5)$ & $169(64.5)$ & 0.954 & 1.016 & $0.592-1.744$ \\
\hline PAD & $87(49.4)$ & 89 (50.6) & $<0.001$ & 3.910 & $2.402-6.365$ \\
\hline Ulcer grade $(\geq 4)$ & $94(52.8)$ & $84(47.2)$ & $<0.001$ & 5.953 & $3.544-10.002$ \\
\hline Wound infection & 99 (38.4) & $159(61.6)$ & 0.041 & 1.806 & $1.024-3.183$ \\
\hline Proteinuria & $54(44.6)$ & $67(55.4)$ & 0.021 & 1.724 & $1.084-2.741$ \\
\hline $\mathrm{HbA1c}<7 \%$ & $3(17.6)$ & $14(82.4)$ & 0.097 & 0.278 & $0.062-1.259$ \\
\hline 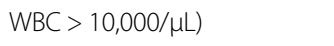 & $78(44.3)$ & $98(55,7)$ & 0.001 & 2.412 & $1.413-4.118$ \\
\hline ESR > 20 (mm/hour) & $100(38.9)$ & $157(61.1)$ & 0.171 & 2.454 & $0.678-8.877$ \\
\hline Osteomyelitis & $59(64.8)$ & $32(35.2)$ & $<0.001$ & 5.879 & $3.462-9.983$ \\
\hline Anemia & $71(39.4)$ & 109 (60.6) & 0.098 & 1.466 & $0.932-2.305$ \\
\hline Renal impairment & $29(43.9)$ & $37(56.1)$ & 0.100 & 1.585 & $0.916-2.743$ \\
\hline
\end{tabular}

PAD peripheral artery disease, HbA1c glycated hemoglobin, WBC white blood cells, ESR erythrocyte sedimentation rate. Note: $P$ value entries in boldface denote statistical significance

persisted as an independent risk factor for LEA, increasing amputation risk by more than five times and emerging as the second strongest risk factor after duration of ulcer. This is consistent with many previous studies $[19,25,28]$ and suggests that deep infections rather than infection per se plays more significant role on diabetic foot amputations.

Over three-quarter of our subjects presented with diabetic peripheral neuropathy (DPN), a well recognized risk factor for foot ulceration. However we did not observe a significant association between DPN and LEA contrary to the observations by Sadriwala et al. [28]. Our finding is supported by robust evidence as most researchers in this area have similarly documented a lack of association between DPN and LEA [20, 21, 24]. This raises the possibility that tissue denervation does not significantly impair wound healing in an offloaded foot. On the other hand, the presence of PAD independently increased the probability of LEA by nearly three-folds in our study, an observation that is consistent with most $[19,21,24,28]$ but a few [20] studies in this subject area.

Table 3 Multivariate predictors of amputation

\begin{tabular}{llllll}
\hline & B & Adjusted O.R & $P$ value & \multicolumn{2}{c}{ 95\% C.I.for OR } \\
\cline { 5 - 7 } & & & & Lower & Upper \\
\hline Ulcer $>1$ month & 2.331 & 10.3 & $<0.001$ & 4.055 & 26.132 \\
PAD & 1.025 & 2.8 & $<0.001$ & 1.520 & 5.107 \\
Osteomyelitis & 1.726 & 5.6 & $<0.001$ & 2.930 & 10.776 \\
\hline
\end{tabular}

$P A D$ peripheral artery disease
The process of wound granulation and healing requires adequate nutrient supply to the tissues and this is adversely affected in the presence of circulatory compromise [29]. Evidence has also recently emerged that PAD reduces tissue antibiotic concentration and increases proliferation of multidrug resistant microbes in diabetic foot wounds with resultant increase in the odds of amputation [30]. In a sub-analysis of the Eurodiale study, a multi-center observational study across 14 centers in Europe, Prompers et al. [31] reported that when the cohort was stratified according to presence or absence of PAD, wound infection emerged as the specific predictor of LEA in PAD patients only. This led the authors to conclude that the negative effect of infection on wound healing is restricted only to patients with PAD.

One factor that has emerged nearly always as a significant risk factor for LEA is ulcer grade [19, 20, 22, 27, 28]. This was confirmed in our study which showed that Wagner grade 4 ulcer and above increased LEA risk nearly six times. This observation is not surprising since ulcer severity including ulcer depth and probability of gangrene increases with higher Wagner grade. The presence of proteinuria emerged as a significant risk factor for LEA in this study. Proteinuria may be a sign of nephropathy in persons with diabetes. Although we did not quantify the degree of proteinuria nor measure serum albumin, our finding may be accounted for by hypoalbuminemia which has been shown to predispose to wound infection and delayed wound healing [32]. 
Research findings on the influence of glycemic control on amputation risk have been largely inconsistent. While a few authors have observed a significant association between the two [21, 28, 33], others have reported otherwise [22, 27]. Our study is one of those which failed to show any significant association between HbA1C and LEA. In fact in the study by Lee et al. [34], baseline HbA1c was even significantly higher in treatment success group than those who suffered LEA. These findings suggest that although poor glycemia is a potent risk factor for development of DFU, it is not necessarily a significant determinant of amputation in the patients.

Some authors have reported significant positive predictive value of acute phase reactants including WBC count, C-reactive protein and ESR on DFU-related LEA $[35,36]$. However our observations contradict such findings. In agreement with the works of Pemayun et al. [21], we did not observe any significant effect of ESR on the odds of amputation. Increased white cell count showed promise of predicting LEA with unadjusted odds ratio of 2.4 but when adjusted for other covariates in multivariate analysis, no significant predictability was detected. Levels of CRP behaved the same way in a recent study in Saudi Arabia [20]. Prior to that, a Malaysian study had reported the inability of WBC, CRP and ESR to predict amputation in patients with DFU [37]. These observations support the argument that elevated levels of acute phase reactants in DFU patients is only secondary to other more important underlying pathologies such as limb ischemia, wound infection and osteomyelitis as suggested by Wang et al. [20]. Anemia is widely reported to impair wound healing $[23,38]$ and is expected to play a role in diabetic foot amputation. However, we did not observe any significant association between anemia and LEA, in concordance with reports of other investigators on this subject [21,37]. This finding however contradicts the report by Yesil et al. [19] and Sun et al. [22] who observed significant associations between baseline hemoglobin concentrations and risk of LEA. Unlike other variables investigated against outcome in this study, anemia is usually quickly corrected with blood transfusion soon after hospitalization and this might have obscured its impact on wound healing and LEA in this study.

\section{Strengths and limitations}

To our knowledge, the MEDFUN is the largest and the only multi-center study on diabetic foot ulcer not only in Nigeria but also in West-Africa; and the only study that extensively investigated the determinants of LEA in patients with DFU in this sub-region. Secondly, our study centers covered 4 out of the six geo-political zones of Nigeria. Since the remaining 2 geo-political zones share common characteristics with one or more of these 4 zones, our results are therefore largely generalizable as a true reflection of the burden of diabetic foot ulcer in Nigeria.

The limitations of this study however need to be highlighted. Firstly, distinction between type I and type II DM was made clinically as commonly practiced in most hospitals in Nigeria due to absence of facilities for routine anti-GAD 65 and plasma C-peptide assays. This may lead to misclassification of subjects by diabetes type. Secondly, our inability to conduct vascular imaging of the lower limbs for all the participants constitutes another limitation. Due to financial difficulties, only subjects with clinical suspicion of PAD underwent Doppler ultrasound. This has the potential of under diagnosing the condition due to observer bias. The ankle brachial index (ABI) which is a standard bedside screening tool for PAD could also not be utilized in this study due to technical problems associated with applying pressure cuffs on infected wounds and inflamed surrounding skin. Finally, each of the participating centers adopted its own DFU management protocol based on availability of manpower, and the decision to amputate or not was dependent on the clinicians at each center. It is not unlikely that this lack of uniformity might have affected the outcome of this study. This is also applicable to the clinical measurements which are prone to inter-observer bias and laboratory tests which might have been influenced by performance variations of diagnostic equipments at the different study centers. However, this lack of uniformity is common in studies of this nature, including the widely cited Eurodiale study [31] which was the largest multi-center diabetic foot ulcer study in Europe.

\section{Conclusion}

This study has identified a number of important risk factors for LEA in subjects with DFU and these include duration of ulcer longer than 1 month, PAD, higher Wagner grade, wound infection, proteinuria and osteomyelitis. Interestingly, most of these identified predictors of LEA are factors that can be quickly assessed by the patient's bedside. We believe that the findings in this study would assist general practitioners identify high risk patients who may benefit from early referral to specialist centers, and also guide foot care specialists in taking appropriate and timely clinical decisions. This may go a long way in reducing LEA rate in people with DFU in our environment.

\section{Abbreviations \\ DFU: Diabetic foot ulcer; DM: Diabetes mellitus; DPN: Diabetic peripheral neuropathy; ESR: Erythrocyte sedimentation rate; HbA1c: Glycated hemoglobin; LEA: Lower extremity amputation; MEDFUN: Multi-center Evaluation of Diabetic Foot Ulcer in Nigeria; PAD: Peripheral artery disease; T1DM: Type 1 diabetes mellitus; T2DM: Type 2 diabetes mellitus; WBC: White blood cell}

Acknowledgements Not applicable. 


\section{Authors' contributions}

All authors contributed significantly at every stage of this study. EU conceptualized and designed the study protocol, and developed the manuscript. All authors took part in data collection. OA, IG and IO participated in data analysis and interpretation. ME and IE critically reviewed the manuscript for intellectual content. All authors read and approved the final manuscript.

\section{Funding}

This study did not receive funding from any external source.

\section{Availability of data and materials}

The datasets used and/or analyzed during the current study are available from the corresponding author on reasonable request.

\section{Ethics approval and consent to participate}

Approval for the study was given by the local Research and Ethics Committee of each of the participating institution. Subjects' participation in this study was voluntary. Verbally granted informed consent was obtained from each patient prior to enrollment into the study.

\section{Consent for publication}

Not applicable.

\section{Competing interests}

The authors declare that they have no competing interests.

\section{Author details}

'Department of Medicine, Division of Endocrinology, Diabetes and Metabolism, Enugu State University of Science and Technology, Enugu, Nigeria. ${ }^{2}$ Department of Medicine, Division of Endocrinology, Diabetes and Metabolism, Lagos State University, Lagos, Nigeria. ${ }^{3}$ Department of Medicine, Division of endocrinology, Diabetes and Metabolism, Bayero University, Kano, Nigeria. ${ }^{4}$ Department of Medicine, Division of Endocrinology, Diabetes and Metabolism, Ahmadu Bello University, Zaria, Nigeria. ${ }^{5}$ Department of Medicine, Division of Endocrinology, Diabetes and Metabolism, Federal Medical Center, Keffi, Nigeria. ${ }^{6}$ Department of Medicine, Division of Endocrinology, Diabetes and Metabolism, Federal Medical Center, Umuahia, Nigeria.

Received: 25 January 2019 Accepted: 4 June 2019 Published online: 14 June 2019

\section{References}

1. The diabetes declaration and strategy for Africa: a call to action and plan of action to prevent and control diabetes and related chronic diseases. Available at https://www.ghdonline.org/uploads/Diabetes_Declaration Strategy_for_Africa_full.pdf. Accessed 23 Dec 2018.

2. Uloko AE, Musa BM, Ramalan MA, Gezawa ID, Puepet FH, Uloko AT, et al. Prevalence and risk factors for diabetes mellitus in Nigeria: a systematic review and meta-analysis. Diabetes Ther. 2018;9(3):1307-16.

3. Olamoyegun M, Ibraheem W, Iwuala S, Audu M, Kolawole B. Burden and pattern of micro vascular complications in type 2 diabetes in a tertiary health institution in Nigeria. Afr Health Sci. 2015;15:1136-41.

4. Singh N, Armstrong DG, Lipsky BA. Preventing foot ulcers in patients with diabetes. JAMA. 2005;293(2):217-28

5. Abbas ZG, Archibald LK. Epidemiology of the diabetic foot in Africa. Med Sci Monit. 2005;11:262-70.

6. Edo A, Edo G, Ezeani I. Risk factors, ulcer grade and management outcome of diabetic foot olcers in a tropical tertiary care hospital. Niger Med J. 2013; 54(1):59-63.

7. Odusan O, Amoran OE, Salami O. Prevalence and pattern of Diabetic Foot Ulcers among adults with Diabetes mellitus in a secondary health care facility in Lagos, Nigeria. Annals of Health Research. 2017;3(2):98-104.

8. Anumah FO, Mshelia-Reng R, Abubakar A, Sough T, Asudo F, Jamda MA, et al. Management outcome of diabetic foot ulcers in a teaching hospital in Abuja, Nigeria. J Diabetes Foot Complications. 2017;9(1):15-20.

9. Rice JB, Desai U, Cummings AK, Birnbaum HG, Skornicki M, Parsons NB. Burden of diabetic foot ulcers for medicare and private insurers. Diabetes Care. 2014;37:651-8.
10. Ekpebegh $\mathrm{CO}$, Iwuala SO, Fasanmade $\mathrm{OA}$, Ogbera $\mathrm{AO}$, Igumbor $\mathrm{E}$ Ohwovoriole AE. Diabetes foot ulceration in a Nigerian hospital: in-hospital mortality in relation to the presenting demographic, clinical and laboratory features. Int Wound J. 2009;6(5):381-5.

11. Cancelliere Pasquale. Current epidemiology of diabetic foot ulcers. Int J Diabetes. 2016:1:12-4.

12. Karam J, Shepard A, Rubinfeld I. Predictors of operative mortality following major lower extremity amputations using the National Surgical Quality Improvement Program public use data. J Vasc Surg. 2013;58:1276-82.

13. Desmond D, Gallagher P. In: Preedy VR, Watson RR, editors. Quality of life in people with lower limb amputation. Handbook of disease burdens and quality of life measures; 2010. p. 3785-96.

14. Lavery LA, Hunt NA, Ndip A, Lavery DC, Van Houtum W, Boulton AJ. Impact of chronic kidney disease on survival after amputation in individuals with diabetes. Diabetes Care. 2010:33:2365-9.

15. Hoffmann M, Kujath P, Flemming A, Proß M, Begum N, Zimmermann M, et al. Survival of diabetes patients with major amputation is comparable to malignant disease. Diab Vasc Dis Res. 2015;12:265-71.

16. Baba M, Davis WA, Norman PE, Davis TM. Temporal changes in the prevalence and associates of diabetes-related lower extremity amputations in patients with type 2 diabetes: the Fremantle diabetes study. Cardiovasc Diabetol. 2015;14:152.

17. Stoekenbroek RM, Lokin JLC, Nielen MM, Stroes ESG. How common are foot problems among individuals with diabetes? Diabetic foot ulcers in the Dutch population. Diabetologia. 2017;60:1271-5.

18. Ugwu E, Adeleye O, Gezawa I, Okpe I, Enamino M, Ezeani I. Burden of diabetic foot ulcer in Nigeria: current evidence from the multicenter evaluation of diabetic foot ulcer in Nigeria. World I Diabetes. 2019;10(3):200-11.

19. Yesil S, Akinci B, Yener S, Bayraktar F, Karabay O, Havitcioglu H, et al. Predictors of amputation in diabetics with foot ulcer: single center experience in a large Turkish cohort. Hormones (Athens). 2009;8:286-95.

20. Wang DD, Jamjoom RA, Alzahrani AH, Hu FB, Alzahrani HA. Prevalence and correlates of lower-extremity amputation in patients with diabetic foot ulcer in Jeddah, Saudi Arabia. Int J Low Extrem Wounds. 2016;15(1):26-33.

21. Pemayun TGD, Naibaho RM, Novitasari D, Amin N, Minuljo TT. Risk factors for lower extremity amputation in patients with diabetic foot ulcers: a hospital-based casecontrol study. Diabetic Foot Ankle. 2015;6:29629. https:/doi.org/10.3402/dfa.v6.29629.

22. Sun JH, Tsai JS, Huang CH, Lin CH, Yang HM, Chan YS, et al. Risk factors for lower extremity amputation in diabetic foot disease categorized by Wagner classification. Diabetes Res Clin Pract. 2012;95:358-63.

23. Guo S, Dipietro LA. Factors affecting wound healing. J Dent Res. 2010;89(3): 219-29.

24. Gershater MA, Löndahl M, Nyberg P, Larsson J, Thörne J. Eneroth et al.. Complexity of factors related to outcome of neuropathic and neuroischemic/ischemic diabetic foot ulcers: a cohort study. Diabetologia. 2009;52:398-407.

25. Uysal S, Arda B, Taşbakan MI, Çetinkalp Ş, Şimşir IY, Öztürk AM, et al. Risk factors for amputation in patients with diabetic foot infection: A prospective study. Int Wound J. 2017;14(6):1219—24.

26. Lavery LA, Armstrong DG, Wunderlich RP, Mohler MJ, Wendel CS, Lipsky BA. Risk factors for foot infections in individuals with diabetes. Diabetes Care. 2006;29:1288-93.

27. Tabur S, Eren MA, Celik Y, Dağ OF, Sabuncu T, Sayiner ZA, et al. The major predictors of amputation and length of stay in diabetic patients with acute foot ulceration. Wien Klin Wochenschr. 2015;127:45-50.

28. Sadriwala Q, Gedam B, Akhtar M. Risk factors of amputation in diabetic foot infections. Int Surg J. 2018:5:1399-402.

29. Halloran CM, Slavin JP. Pathophysiology of wound healing. Surgery. 2002;5:1-5.

30. Aysert YP, Ozdil T, Dizbay M, Guzel TO, Hizel K. Peripheral arterial disease increases the risk of multidrug-resistant bacteria and amputation in diabetic foot infections. Turk J Med Sci. 2018;48(4):845-50.

31. Prompers L, Schaper N, Apelqvist J, Edmonds M, Jude E, Mauricio D, et al. Prediction of outcome in individuals with diabetic foot ulcers: focus on the differences between individuals with and without peripheral arterial disease. The Eurodiale study. Diabetologia. 2008:51:747-55.

32. Sindgikar V, Narasanagi B, Tejasvini V, Ragate A, Patel FA. Effect of serum albumin in wound healing and its related complications in surgical patients. Al Ameen J Med Sci. 2017;10(2):132-5.

33. Resnick HE, Carter EA, Sosenko JM, Henly SJ, Fabsitz RR, Ness FK, et al. Incidence of lower-extremity amputation in American Indians: the strong heart study. Diabetes Care. 2004;27:1885-91. 
34. Lee KM, Kim WH, Lee JH, Choi MSS. Risk factors of treatment failure in diabetic foot ulcer patients. Arch Plast Surg. 2013;40:123-8.

35. Lipsky BA, Sheehan P, Armstrong DG, Tice AD, Polis AB, Abramson MA. Clinical predictors of treatment failure for diabetic foot infections: data from a prospective trial. Int Wound J. 2007:4:30-8.

36. Akinci B, Yener S, Yesil S, Yapar N, Kucukyavas Y, Bayraktar F. Acute phase reactants predict the risk of amputation in diabetic foot infection. J Am Podiatr Med Assoc. 2011;101:1-6.

37. Yusof NM, Rahman JA, Zulkifly AH, Che-Ahmad A, Khalid KA, Sulong AF, et al. Predictors of major lower limb amputation among type II diabetic patients admitted for diabetic foot problems. Singap Med J. 2015;56(11):626-31.

38. Broughton $G$, Janis JE, Attinger CE. The basic science of wound healing. Plast Reconstr Surg. 2006;117(7):12-34.

\section{Publisher's Note}

Springer Nature remains neutral with regard to jurisdictional claims in published maps and institutional affiliations.

Ready to submit your research? Choose BMC and benefit from:

- fast, convenient online submission

- thorough peer review by experienced researchers in your field

- rapid publication on acceptance

- support for research data, including large and complex data types

- gold Open Access which fosters wider collaboration and increased citations

- maximum visibility for your research: over $100 \mathrm{M}$ website views per year

At BMC, research is always in progress.

Learn more biomedcentral.com/submissions 